\title{
First morning urinary albumin concentration is a good predictor of 24-hour urinary albumin excretion in children with Type 1 (insulin-dependent) diabetes
}

\author{
C.T. Cowell, S. Rogers and M. Silink \\ Department of Endocrinology, The Children's Hospital, Camperdown, Sydney, Australia
}

\begin{abstract}
Summary. Twenty-four hour urinary albumin excretion was measured in 97 children with Type 1 (insulin-dependent) diabetes and found to have a geometric mean of $6 \mathrm{mg} /$ day (range $1-38 \mathrm{mg} / \mathrm{d}$ ). The same geometric mean of $6 \mathrm{mg} /$ day (range $1-45 \mathrm{mg} / \mathrm{d}$ ) was found in 120 normal children. The relationship of 24-h urinary albumin excretion to the albumin concentration $(\mathrm{mg} / \mathrm{l})$ and to the ratio of albumin: creatinine (mg:mmol) on first morning urine samples in 64 patients was highly significant $(r=0.93$ and $r=0.62$ respectively, $p<$ 0.001 ). In 41 patients, the relationship between 24 -h urinary albumin excretion and albumin concentration upon urine samples at various times was assessed. The correlation was
\end{abstract}

highest on the first morning sample $(r=0.86) ; 09.00 \mathrm{~h}$ to $13.00 \mathrm{~h}, 0.51 ; 13.00 \mathrm{~h}$ to $18.00 \mathrm{~h}, 0.68 ; 18.00 \mathrm{~h}$ to $23.00 \mathrm{~h}, 0.32$. High sensitivity and moderate specificity was obtained using a first morning albumin concentration of greater than $20 \mathrm{mg} / 1$ to detect increased albumin excretion. These results show that the measurement of albumin concentration on the first morning urine sample can be used for a screening test for microalbuminuria in children.

Key words: Type 1 (insulin-dependent) diabetes, microalbuminuria, children, albumin: creatinine, first morning albumin concentration.
The major cause of increased mortality in Type 1 (insulin-dependent) diabetes is associated with the development of diabetic nephropathy; this occurs in $45 \%$ of individuals [1]. There are now three studies [2-4] which have shown that a minor increase in albumin excretion rate (AER) or urinary albumin excretion (UAE), also known as microalbuminuria, in individuals with Type 1 diabetes is a predictor of the development of diabetic nephropathy. The possibility that renal nephropathy at this stage may be reversible [5] has led to the need to develop screening tests for microalbuminuria. Jarrett et al. [6] have recently discussed the problems in defining increased AER, as there is no standardization of urine collections nor is there a consensus on the level of AER which may be considered elevated. When considering a screening test for microalbuminuria, the collection of 24-h urine samples is inconvenient and often not practical - especially in children and women. Hence overnight urine collections have commonly been used to measure AER $[2,7]$. Overnight urine collection has an additional advantage of avoiding the considerable variability in AER which is seen in daytime samples as a result of posture, exercise and possibly diet. Recently Gatling et al. [8] found that measuring the albumin concentration on an overnight urine sample is a good pre- dictor of an AER greater than $30 \mu \mathrm{g} / \mathrm{min}$ (i.e. greater than $43 \mathrm{mg} /$ day), and suggested that measuring the albumin concentration on rising may be a suitable screen for elevated AER.

In looking for a suitable screening test for elevated AER in children with Type 1 diabetes, we have examined the relationship between 24-h AER and albumin concentration measured on first morning urine samples (FMAC) and samples collected at other times of the day. In addition, we have looked at the relationship between 24-h UAE and the ratio of albumin: creatinine on the same samples.

\section{Subjects and methods}

\section{Subjects}

Twenty-four-hour urine collections were obtained in 97 children, mean age 11 years (range 2-19 years), 40 males, 57 females, with Type 1 (insulin-dependent) diabetes, mean duration three years (range 1 week to 13 years), while inpatients at the Children's Hospital, Sydney, Australia. In 64 patients a sample from the first morning urine specimen during a 24 -h collection was obtained. In 41 patients a sample was obtained each time the child passed urine during the 24-h collection. In eleven children with clinically stable diabetic control and 


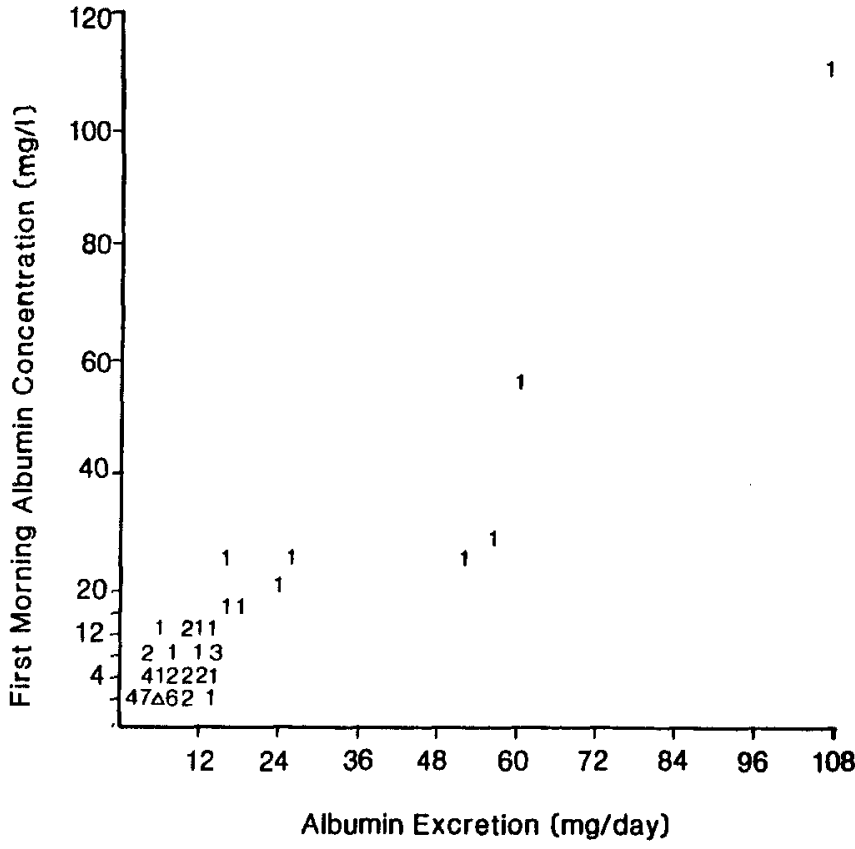

Fig. 1. Relationship between first morning urinary albumin concentration and albumin excretion in 64 patients with Type 1 (insulin-dependent) diabetes $(r=0.93 ; p<0.001) . \Delta=10$

Table 1. Correlation of 24-h albumin excretion and random urine samples in 41 patients with Type 1 (insulin-dependent) diabetes

\begin{tabular}{|c|c|c|c|}
\hline \multirow[t]{2}{*}{ Time of collection } & \multirow{2}{*}{$\begin{array}{l}\text { No. of } \\
\text { samples }\end{array}$} & \multicolumn{2}{|l|}{ Correlation } \\
\hline & & $\begin{array}{l}\text { Albumin } \\
\text { concentration } \\
(\mathrm{mg} / \mathrm{l})\end{array}$ & $\begin{array}{l}\text { Albumin: } \\
\text { creatinine } \\
(\mathrm{mg} / \mathrm{mmol})\end{array}$ \\
\hline First morning & 41 & 0.86 & 0.74 \\
\hline $09.00 \mathrm{~h}-13.00 \mathrm{~h}$ & 49 & 0.51 & 0.43 \\
\hline $13.00 \mathrm{~h}-18.00 \mathrm{~h}$ & 56 & 0.68 & 0.54 \\
\hline $18.00 \mathrm{~h}-23.00 \mathrm{~h}$ & 55 & 0.32 & 0.44 \\
\hline
\end{tabular}

normal UAE, three consecutive 24-h urine samples with concurrent first morning urine samples were obtained. The day to day variability of 24- $\mathrm{h}$ UAE and the FMAC was expressed as the coefficient of variation of the three sample days.

A normal range of 24-h urinary albumin excretion was obtained in 120 school children, mean age 9.6 years (range 3.5-15 years), 49 males, 71 females, who were not known to have renal disease. In 111 of these children a concurrent first morning urine sample was also obtained. The urine samples were collected without preservative and were stored at $-20^{\circ} \mathrm{C}$ until assayed. Informed consent was obtained from the families involved and approval was given for the project by The Children's Hospital Ethical Committee.

\section{Methods}

Urinary albumin was measured by a double antibody radioimmunoassay based on the method of Keen et al. [9]. The detection limit of the assay was $2 \mathrm{ng} /$ tube. Using this assay, we were able to detect albumin concentrations as low as $10 \mu \mathrm{g} / 1$. The interassay and intraassay coefficents of variation at three levels were as follows: High $(210 \mu \mathrm{g} /$ l) $9.5 \%, 5.7 \%$; medium $(101 \mu \mathrm{g} / \mathrm{l}), 10.7 \%, 6.8 \%$; low $(45 \mu \mathrm{g} / \mathrm{l}), 20 \%$, $11.6 \%$.
Creatinine was measured by a semiautomated picric acid method with interassay and intraassay coefficients of variation at $4 \%$ and $2 \%$ respectively.

\section{Statistical analysis}

The ratio of albumin: creatinine on urine samples was expressed as $\mathrm{mg}$ albumin per mmol creatinine. The data on 24-h UAE was not normally distributed and showed a positive skew. This required $\log$ ten transformation to achieve a Gaussian distribution for statistical analysis. The geometric mean and $95 \%$ range limits were calculated from the antilog of the mean of the transformed data and twice its standard deviation. Student's t-test and Pearson's correlation coefficient were used for statistical analysis.

\section{Results}

In the 97 children with Type 1 diabetes, the 24-h UAE geometric mean was $6 \mathrm{mg}$ /day (range $1-38 \mathrm{mg}$ /day). The same geometric mean of $6 \mathrm{mg} /$ day (range $1-45 \mathrm{mg} / \mathrm{d}$ ) was found in the 120 normal children. There was no sex difference in either group.

Figure 1 shows the relationship between albumin concentration on the first morning urine specimen and 24-h UAE in 64 children with Type 1 diabetes $(r=0.93$, $p<0.001)$. When the 4 children with 24 -h UAE greater than $30 \mathrm{mg} /$ day are not included in the analysis (see Fig. 1), there remains a strong correlation between FMAC and 24-h UAE $(r=0.72, p<0.001)$. A similar strong correlation exists between FMAC and 24-h UAE in the 111 normal children $(r=0.77, p<0.001)$, and also between 24-h UAE and the ratio of albumin: creatinine $(r=0.72, p<0.001)$. The relationship between 24 -h $\mathrm{UAE}$ and the ratio of albumin:creatinine is not as strong in the 64 children with Type 1 diabetes $(r=0.62$, $p<0.001$ ); when the 4 children with UAE greater than $30 \mathrm{mg} /$ day are excluded, the correlation decreases $(r=0.42, p<0.001)$.

In 41 children urine samples were obtained at various times of the day. This allowed examination of the relationship of 24-h UAE with albumin concentration and with the ratio of albumin: creatinine on these samples (Table 1). At all times of the day, measurement of urinary albumin concentration showed a stronger correlation with 24-h UAE than did the measurement of albumin: creatinine ratio. The strongest correlation of albumin concentration with the 24-h UAE was seen on the first morning urine sample (FMAC); a much weaker correlation was seen on the urine samples collected at other times of the day.

The day to day variability of albumin excretion was assessed in 11 children with clinically stable diabetic control by measurement of 24-h UAE and FMAC collected on 3 consecutive days. There was a mean coefficient of variation of $39 \%$ (range $6-68 \%$ ) on the $24-\mathrm{h}$ $\mathrm{UAE}$ and a mean coefficient of variation of $43 \%$ (range $16-79 \%$ ) on FMAC.

An assessment was made of the value of using FMAC greater than $20 \mathrm{mg} / 1$ as a screening test to pre- 
dict 24-h UAE of greater than $20 \mathrm{mg} /$ day. Although 24-h UAE of greater than $20 \mathrm{mg} /$ day is within the normal range, its value was chosen to maximize the sensitivity of the screening test (i.e. to minimize the number of false negative results). The sensitivity of this test was $100 \%$ and the specificity $57 \%$. The other time intervals gave less satisfactory results. Sensitivities were $17 \%$, $50 \%, 67 \%$, and the corresponding specificities were $50 \%, 33 \%$ and $50 \%$.

\section{Discussion}

It is likely that screening for microalbuminuria using sensitive immunoassays will become an essential part of the management of individuals with Type 1 (insulin-dependent) diabetes as a consequence of the previously mentioned studies [2-4]. The interpretation of these studies, which shows that minor increases in AER predict the development of diabetic nephropathy and that this may be a potentially reversible abnormality, requires caution since the study populations are small.

Our results indicate that measurement of albumin concentration on the first morning urine sample is a good indicator of 24-h UAE. It is encouraging to note that a strong correlation exists between FMAC and 24-h UAE even in those individuals with albumin excretion well within the normal range. Correlation of albumin concentration to 24-h UAE at other times of the day was not as strong. This may be due to the effects of posture and exercise on albumin excretion. We have not attempted to investigate these effects, but have noted that children with orthostatic proteinuria had low FMAC and considerably higher urinary albumin concentrations at other times of the day. Orthostatic proteinuria would not give a falsely positive result if FMAC were used to screen for microalbuminuria in diabetes.

Whilst the ratio of protein:creatinine on random urine samples has been used as a reliable indicator of 24-h urinary protein excretion [10], we found no advantage in the use of this ratio (albumin: creatinine) as compared to the measurement of albumin concentration for estimating 24-h UAE. Our data in children with Type 1 diabetes whose AER is in the normal range or is slightly elevated indicate that FMAC gave the most reliable estimate of 24-h UAE.

The considerable day to day variation observed in 24-h UAE and in FMAC in the 11 stable diabetic patients does not affect the clinical interpretation of a normal result. However, the interpretation of borderline $a b-$ normal results does require caution in view of this variability. Furthermore, this variability in $24-h$ UAE and FMAC may be considerably increased in poorly controlled patients, especially when dynamic changes in diabetic control occur. We have observed variability this in preliminary studies in newly diagnosed and unstable diabetic patients (unpublished observations).

The measurement of FMAC is a suitable screening test for microalbuminuria. It is simple and convenient for the individual to perform, is highly sensitive and relatively specific. Further evaluation is required to establish the day to day variability of FMAC in an individual and to determine its use for screening large populations.

Acknowledgements. This work has been supported by grants from $\mathrm{Mr}$ R.R.Williams and the C.E.Heath Company, the Diabetes Youth Foundation of Australia and Novo Laboratories (Australia). We thank C. Hobson for help with the manuscript.

\section{References}

1. Andersen AR, Christiansen JS, Anderson JK, Kreiner S, Deckert $T$ (1983) Diabetic nephropathy in Type 1 (insulin-dependent) diabetes: an epidemiological study. Diabetologia 25: 496-501

2. Viberti GC, Jarrett RJ, Mahmud U, Hill RD, Argyropoulos A, Keen H (1982) Microalbuminuria as a predictor of clinical nephropathy in insulin-dependent diabetes mellitus. Lancet 1: $1430-1432$

3. Parving $\mathrm{HH}$, Oxenboll B, Svendsen PAa, Sandahl Christiansen $\mathrm{J}$ Andersen AR (1982) Early detection of patients at risk of developing diabetic nephropathy. A longitudinal study of albumin excretion. Acta Endocrinol 100: 550-555

4. Mogensen CE, Christensen CK (1984) Predicting diabetic nephropathy in insulin-dependent patients. $N$ Engl $J$ Med 311: $89-93$

5. Viberti G, Keen H (1984) The patterns of proteinuria in diabetes mellitus. Relevance to pathogenesis and prevention of diabetic nephropathy. Diabetes 33:686-692

6. Jarrett RJ, Viberti GC (1985) Risk of nephropathy in diabetes mellitus: problems of methodology and terminology. Diabetologia 28: 181

7. Davies AG, Price DA, Postlethwaite RJ, Addison GM, Burn JL, Fielding BA (1985) Renal function in diabetes mellitus. Arch Dis Child 60: 299-304

8. Gatling W, Knight C, Hill RD (1984) Screening for diabetic nephropathy: which urine sample? Diabetologia 27: 277 - Abstract

9. Keen H, Chlouverakis C (1963) An immunoassay method for urinary albumin at low concentrations. Lancet 2:913-916

10. Shaw AB, Risdon P, Lewis-Jackson JD (1983) Protein creatinine index and albustix in assessment of proteinuria. Br Med $\mathrm{J} 287$ : 929-932

Received: 27 June 1985

and in revised form: 5 November 1985

Dr. Christopher T. Cowell

Department of Endocrinology

The Children's Hospital

Camperdown, Sydney, Australia 